\title{
CONTROLLED RELEASE PRODUCTS FOR MANAGING INSECT PESTS
}

\author{
Faleiro J.R., '; Al-Shawaf,A.M. '; Al-Dandan, A.M. ${ }^{2}$; Al-Odhayb,A. ${ }^{3}$; Al-Rudayni, A. '; Abdallah, A.B.' ; Peixoto, M.P. \\ ${ }^{4}$; Vargas, R. ${ }^{5}$; Bottom, M. ${ }^{6}$; Chidi, S. ${ }^{7}$; Borges, R. ${ }^{8}$; Mafra-Neto, A. ${ }^{9}$ Centre for Date Palm \& Dates in \\ Al-Hassa, Ministry of Agriculture, Saudi Arabia; ${ }^{2}$ Ministry of Agriculture in Al-Hasa, Saudi Arabia; ${ }^{3}$ Directorate of \\ Agriculture in Al-Qassim, Ministry of Agriculture, Saudi Arabia; ${ }^{4}$ Instituto Federal Goiano, Rio Verde Campus, \\ GO, Brazil; ${ }^{5}$ Daniel K. Inouye U. S. Pacific Basin Agricultural Research Center, USDA ARS, Hilo, HI, U.S.; \\ ${ }^{6}$ Embrapa Grape \&Wine, Santa Rita, Bento Gonçalves, RS, Brazil; ${ }^{7}$ Arysta LifeScience, São Paulo, SP, Brazil; 8 ISCA \\ Tecnologias, ljui, RS, Brazil; ${ }^{A}$ Agenor Mafra-Neto, ISCA Technologies, Inc., I 230 Spring St., Riverside, CA 92507, \\ USA (corresponding author: president@iscatech.com)
}

Keywords: pest management, semiochemicals, attract and kill, formulation technology

From 1900-2000, the global human population grew by more than $400 \%$, from 1.5 to 6.1 billion (Roser, 2015). The demands that the current population places upon global food supplies presents what may be one of the greatest challenges of the modern age. To support such a large population in a reliable, sustainable manner, productivity of agricultural crops will have to be improved significantly, most likely through multiple means (development of new, higher-yield crops; more efficient water use; improved cropping systems). One active area of research is the development of more effective methods of agricultural pest management.

For much of contemporary history, insect pest management has relied predominantly on conventional insecticides. These insecticides are typically designed as cover sprays with residues covering the entire crop, with the aim of reducing or eliminating the pest population in the treated field. Since the days of Silent Spring (Carson, 1962), there has been widespread concern over the potential hazards of traditional insecticides to workers, consumers, and the environment, leading to increasingly stringent regulation of their use. Though steps have been taken to minimize the risks posed by pesticide applications, public perception of the suitability of these chemicals remains negative. Over time, more robust regulation may result in the loss of pest control measures upon which many agricultural producers currently depend. In addition to their questionable long-term availability, traditional insecticides possess a number of other limitations, which make the development of alternative methods of pest control highly desirable.

One of the most harmful of these shortcomings is the vulnerability of conventional insecticides to resistance, the gradual loss of susceptibility of a target insect to a given toxin over time (Varela et al., 1993; Blomefield, 1994; Knight et al., 1994; Sauphanor \& Bouvier, 1995; Campbell et al., 2003). Resistance has been shown to occur more rapidly when a single class of toxicants is applied frequently, without variation, over multiple seasons (Buhler, 2016). Therefore, rotation of multiple classes of insecticide to treat the same field is a crucial safeguard to circumvent resistance development, making the loss of more and more pesticide molecules to deregulation an even greater threat to effective long-term pest control.

For these reasons, extensive research has been conducted into an alternative control method, requiring no or minimal use of chemical toxicants: semiochemical-based pest management. Semiochemicals - compounds that manipulate insect behavior - possess many advantages over conventional insecticides. Semiochemicals are naturally occurring compounds with short environmental lives, and are generally viewed as safer, for both people and the environment, than traditional pesticides (reviewed in OECD, 2002). Most semiochemicals used in pest management have been species-specific pheromones (produced by members of the same species to communicate with each other, but eliciting no response in other species), and as such, present fewer risks of negative impacts on beneficial insects.

Rather than attempting to eradicate the pest by treating the entire crop with chemical toxicants, semiochemical pest management seeks to reduce pest populations over time, often by non-lethal means, such as mating disruption, which involves application of synthetic sex pheromones to interfere with male insects' ability to locate a mate (Witzgall et al., 2010). Another promising strategy of semiochemical control is attract and kill (A\&K), which consists of blending a semiochemical attractant with a small quantity of toxicant. A\&K techniques reduce the amount of pesticide applied per unit area compared to traditional cover sprays, and enable more selective application methods, maximizing impact on the target pest while minimizing risks of crop or environmental contamination, worker exposure, and harmful effects on non-targets. A\&K formulations are also less susceptible to the development of resistance: the attractant can typically be formulated with a variety of different toxicants, depending on which insecticides work best against the target insect in a given environment, and on regulatory requirements.

Despite these advantages, semiochemical products have seen limited adoption compared to traditional insecticides. Reasons for this limited success are varied. Conventional pesticides have dominated the market for so long that it is difficult for new alternatives to gain traction (technology "lock in"). Additionally, semiochemicals are often applied as 
one component of an integrated approach to pest management, and so require more in-depth knowledge of the pest's behavior and ecology to apply effectively than conventional cover sprays. A key limitation of semiochemical technologies in the eyes of prospective users is the high cost of many semiochemical active ingredients (AIs). The volatile nature of these chemicals demands that a relatively large quantity of the AI be applied over the treated area to sustain season-long control. If semiochemical products are to gain wider acceptance among agricultural producers - especially if they are to be introduced in developing nations, where food production is most challenging to sustain - the affordability and ease-of-use of these products will have to be improved.

One way this optimization may be achieved is the formulation of semiochemical AIs into controlled-release technologies. By extending AI field life (protecting it from environmental degradation, refining AI release rate), we can decrease the amount of semiochemical required to treat the crop effectively, lowering the overall cost of the application. In the past, most controlled-release technologies have been hand-applied devices, such as pouches, polyethylene tubes or ropes, and rubber septa-type dispensers. As these products require an investment of time and manpower that would be difficult to implement in large-scale crops, controlled-release technologies amenable to mechanized application would possess a keen competitive edge over the majority of semiochemical products currently on the market.

ISCA Technologies, a biotech company in Riverside, CA, USA, has spent the past 15 years developing a line of products based on this concept: Specialized Pheromone and Lure Application Technology, or SPLAT ${ }^{\circledR}$. Comprised entirely of food-safe, organic inert ingredients, SPLAT is a flowable, thick-liquid formulation, which is less viscous when agitated by stirring or vibration, but thickens fairly quickly when at rest. This thixotropic property enables a relatively fast and simple application process by manual or mechanical means, producing a series of environmentally hardy, rainfast point sources affixed firmly to the substrates it is applied to in the field. As a liquid formulation, SPLAT can be applied at any number, size, density or spatial pattern of point sources, and so is readily adaptable to the needs of virtually any pest management situation.

SPLAT's flexibility is not limited to its application method, but also extends to a broad variety of target insects, release rates, and control strategies. SPLAT formulations have been developed for numerous insects, including agricultural, forestry, medical, and veterinary pests, using sex pheromones, kairomones (semiochemicals produced by host organisms rather than by the insects themselves), food-based attractants, aggregation pheromones, repellents, and multiple classes of

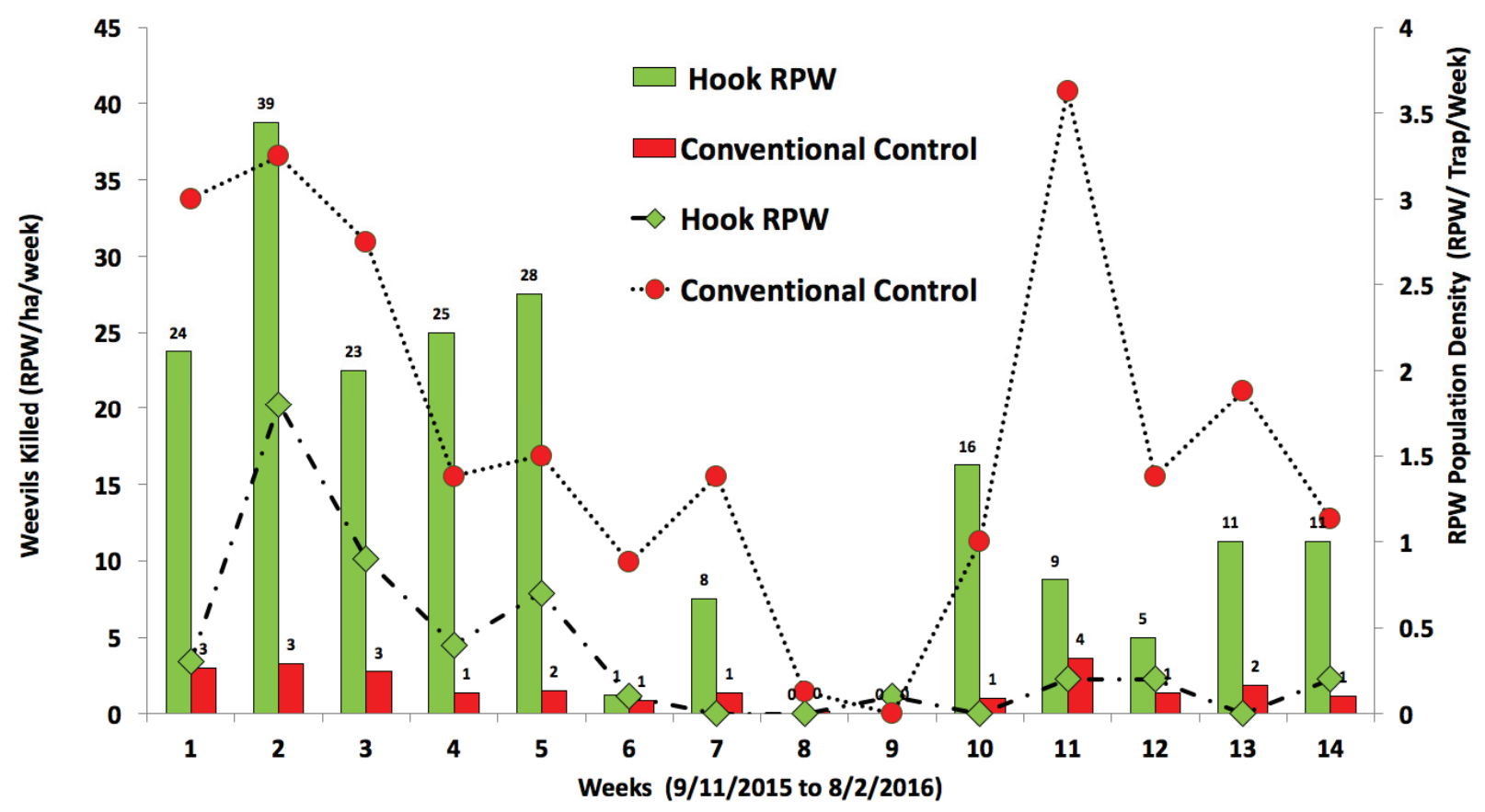

Figure I. RPW control using a single Hook RPW application was compared to a grower's conventional IPM program (the IPM program consisted of mass trapping using a bucket trap per hectare containing an RPW pheromone lure - Chemtica International - 250g of ripe date fruits and water, together with as needed insecticide tree-drench and topical spray applications, and physical removal of detected larval infections). The field trial occurred in fields with similar weevil population densities, and the application of the treatments started at week zero (shown here is a trial in Qassim, Kingdom of Saudi Arabia-KSA). Bar graph shows the total number of adult RPW killed per hectare per week (left vertical axis). Hook RPW (green bars) consistently removed a substantially higher number of adult RPW per hectare per week from the field than the traditionally recommended RPW mass trapping program (red bars). The line graph shows the population density of adult RPW per trap per week in both fields (right vertical axis). Throughout the season the population was significantly higher in the conventional control field (dotted line with red circles) than in the HOOK RPW treated field (dashed line with green diamonds), which indicates that a single HOOK RPW application suppressed the resident weevil's population better than all the combined actions used in the grower's conventional IPM program. It interesting to note that after week six the RPW population in the Hook RPW field was maintained very close to zero RPW/trap/week until the end of the field trial (at week I4), whereas in the grower's conventional IPM program it actually went down to zero for two weeks (weeks 8 and 9), but then the population density spiked to its highest levels soon after that (week II), indicating that Hook RPW seems top control the RPW population more consistently. 
insecticides, deployed in nearly as many different integrated pest management techniques (mating disruption, attract and kill, push-pull strategies, etc.). Through slight alterations in the composition and formulation process, SPLAT can be adjusted to dispense AIs into the environment at biologically active rates for anywhere from one week to over a year, long enough to cover an entire season for many pest species with only one or two applications. SPLAT has been used to control a variety of agricultural pests, including pests of economically important food crops. Of the products available, we wish to discuss three successful A\&K SPLAT formulations designed for the agricultural sector: Hook RPW, SPLAT MAT Spinosad ME, and Noctovi.

Hook RPW targets red palm weevil (RPW), Rhynchophorus ferrugineus, a widespread pest of ornamental, dates and other high-value crops (reviewed in Murphy \& Briscoe, 1999 and EPPO, 2015), which has been documented throughout the Mediterranean, Middle East and Southeast Asia (EPPO, 2015). Through SPLAT technology, Hook RPW combines high knockdown contact insecticide with the powerful aggregation pheromone of RPW, ferrugineol, (Hallett et al., 1993), to create a highly effective, long lasting, control product. A dollop of 3 grams Hook RPW has been shown to be just as effective in attracting adult RPW as the traditional, high maintenance, food baited pheromone traps (El-Shafie et al., 2011). The long field life, and zero maintenance allows the use of Hook RPW as a high density point source A\&K, for example a single application of 400 points of $3 \mathrm{~g}$ Hook RPW per hectare effectively suppress palm weevil populations for more than 3 months in highly infested date palm orchards in Saudi Arabia (El-Shafie et al. 2011, Figure 1,2). This product is an excellent example of the potential for controlled-release technologies like SPLAT to improve practicality and economic feasibility of semiochemical-based pest control.

SPLAT MAT Spinosad ME (or STATIC) targets multiple species of fruit fly pests (Bactrocera spp.) of multiple high-value crops, where they can cause serious damage to fruit, sometimes resulting in almost total crop failure (Wu et al. 2009). Crop losses to these pests can reach hundreds of millions of dollars in California (CDFA, 2015). SPLAT MAT Spinosad ME deploys the parapheromone methyl eugenol (ME) to create an A\&K formulation for male fruit flies (Mafra-Neto et al., 2013). Unlike previous A\&K formulations, which relied on hazardous organophosphate insecticides, this formulation utilizes a reduced risk toxicant, spinosad, produced by soil-dwelling bacterium (Saccharopolyspora spinosa). When tested for its efficacy for Bactrocera dorsalis control in Tahiti, SPLAT MAT Spinosad ME showed equal performance to other male annihilation techniques using conventional pesticides (Leblanc et al., 2011). In Hawaii, SPLAT MAT Spinosad ME formulations were as effective as other ME formulations using conventional pesticides in controlling $B$. dorsalis on papaya (Carica papaya) over a 12 -week period (Vargas et al., 2008). When weathered formulations were tested in guava (Psidium guajava) and grapefruit (Citrus paradisi), SPLAT MAT Spinosad ME formulations showed continued effectiveness and better longevity past the 6-week time point, when other ME formulations became ineffective (Vargas et al., 2008). As with Hook RPW, SPLAT MAT Spinosad ME possesses a great advantage over previous control strategies

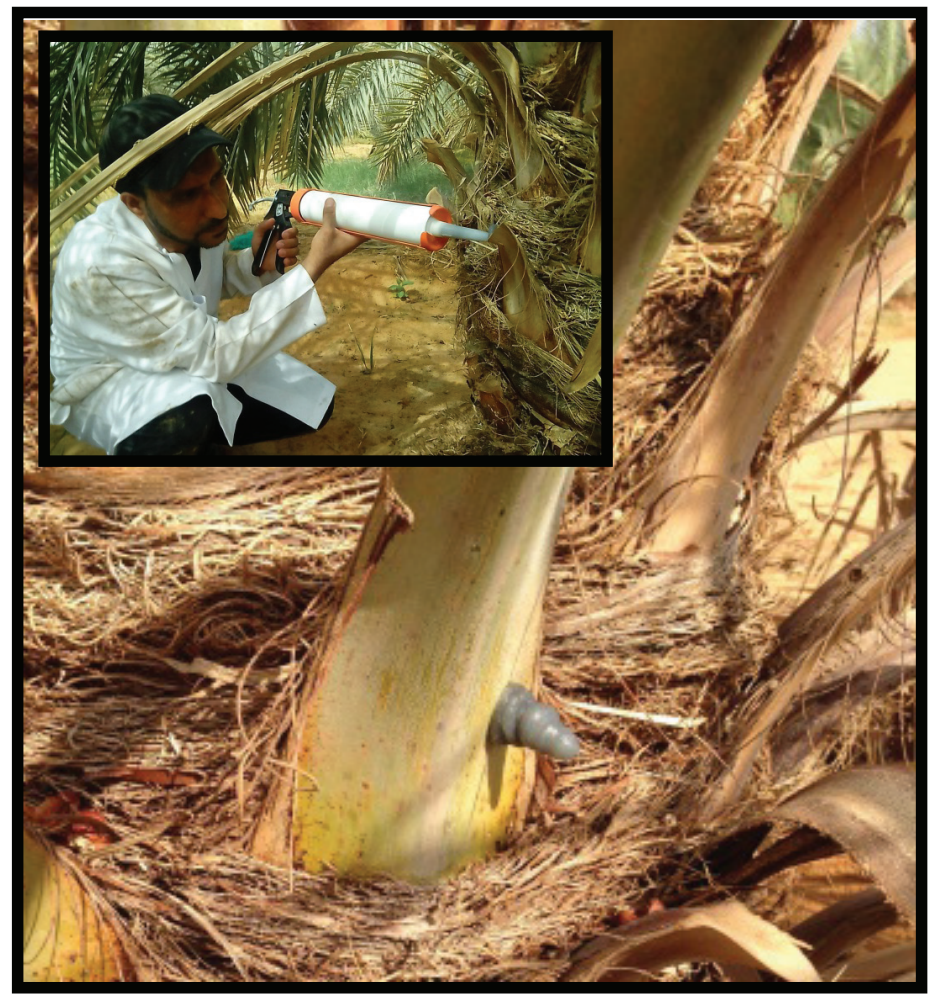

Figure 2. Hook RPW is a long lasting attract and kill formulation that contains small amounts of red palm weevil (RPW) sex pheromone and cypermethrin. The pheromone induces RPW adults to approach and manipulate the formulation, which causes the weevil to get contaminated with deadly doses of the insecticide. The inset shows Hook RPW (packaged in a 750g tube) being applied to a date palm tree using a calibrated applicator. In this case every time the user pulls the trigger the applicator unit delivers a $3 g$ dollop (the gray dollop at the base of the palm frond) to the tree. Hook RPW can be applied in the field at densities up to 400 dollops per ha, depending on the local RPW population and the goals of the pest management program. Chemical analysis of dollop samples collected from this field indicate that after 3.5 months the dollops still contained between 25 and $35 \%$ of the initial pheromone and most of the cypermethrin. Replicated laboratory trials with Hook RPW aged for as long as six months in the field in Saudi Arabia show that adult RPW manipulating a dollop, for as little as a few seconds, die in less than sixty minutes independent of the age of the dollop or the gender of the beetle.

in terms of user-friendliness and speed of application. While most fruit fly A\&K techniques consist of trap-lure systems, SPLAT MAT Spinosad ME is a liquid product that not only can be sprayed using conventional equipment, but it is also amenable to mechanized application, which facilitates its use for area-wide applications - often a highly desirable quality for agricultural pest management (Mafra-Neto et al., 2013).

Noctovi is a tank-mixed A\&K formulation designed to target multiple species of noctuid moths (Lepidoptera: Noctuidae) (Figure 4), globally distributed pests of multiple row crops (e.g. soybean, sorgum, cotton). In order to attract the target pests, Noctovi relies on a blend of plant-based, volatile kairomones. Unlike pheromones, which often manipulate the behavior of only one gender (typically male) (RodriguezSaona \& Stelinski 2009; Hern \& Dorn 1999; Mechaber et al. 2002; Masante-Roca et al. 2007), Noctovi's blend of volatiles have been shown to be attractive to both hungry male and 




SPLAT-MAT TM SPINOSAD ME $\quad$ Malathion + ME Blocks every 20 days

Figure 3. Line graph of the female carambola fruit fly population density in fields treated with either a single application in the beginning of the trial of SPLAT MAT SPINOSAD ME (SPLAT ME treated plots) or fields treated every three weeks with an application of the fruit fly bait Success/GFI20 (DOW Agrosciences) and wooden blocks soaked in a mixture with methyl eugenol and malathion (Brazilian Carambola Fruit Fly Eradication Program treaded plots). SPLAT MAT SPINOSAD ME (blue line) was applied to three fields of 27 ha each at the rate of I00x $3 g$ point sources/ha, to host trees on the first week of October; whereas three fields of 27ha each under the Brazilian Carambola Fruit Fly Eradication Program (red line) continued to be treaded every three weeks with the toxic wooden blocks and the fruit fly bait Success. The data shows that the repeated applications of the Brazilian Carambola Fruit Fly Eradication Program doesn't seem to have a strong suppressive effect on the local population, as seen by the spike in female trap captures starting in January, whereas the single SPLAT MAT SPINOSAD ME application in the beginning of the trial suppressed the carambola fruit fly population to levels close to zero captures per week for the entire four months of the field trial.A rain-fast, long lasting, semiochemical attract and kill formulation, like SPLAT MAT SPINOSAD ME, has the advantage to provide constant population suppression of the pest, without significant gaps in control. The female fruit fly population density was measured by counting the number of female carambola fruit flies captured per week per monitoring McPhail trap (Yellow Ball Trap, ISCA Tech., Riverside, CA) lured with three tablets of torula protein bait (Turula Tablets, ISCA Tech., Riverside, CA) dissolved in $300 \mathrm{ml}$ of water.



Figure 4. Noctovi is a liquid formulation that contains a powerful plant based adult moth attractant, potent phagostimulants that induce the moths to feed on the formulation (picture on the left), which is tank mixed with $2 \%$ of a contact or stomach-based insecticide that kills the attracted adult moths (picture on the right and inset, each brown/gray triangular individual on the ground is a moth killed by the Noctovi Attract and Kill), thus reducing the impact of the next generation of the pest in the field. Noctovi can be manually applied, but most of the application is done mechanically by land (e.g., motorcycles and tractors) or by air (airplanes), where the product is applied as is (not diluted) in the field in a line where about one liter of formulation covers 100 linear meters. The gap separating the lines from each other is 100 meters of crop, so Noctovi is used at II/ha, and the Noctovi application covers less than $1 \%$ of the protected crop. 
female moths; for some moth species it is particularly attractive to gravid females. A management approach using these compounds is particularly desirable for noctuid species, which are often highly resistant to pesticides, and co-occur on the same crops, rendering control by species-specific pheromones economically unfeasible. Noctovi, in Brazilian soybean fields, demonstrated to effectively control of Helicoverpa armigera and Chrysodeixis includens, better than conventional insecticides, improving crop health and yield (Borges et al., 2015). These results were produced using low volume application rates, reducing insecticide inputs by $98 \%$ compared to cover sprays. Noctovi costs the same as conventional pesticides, and is currently sold and used on over 250,000 hectares in Brazil alone. Considering the broad host range of noctuids - tens of millions of hectares of row crops worldwide - this product is a rarity among semiochemical products, in that Noctovi is not limited to high value crops. Development of Noctovi markets provides a unique opportunity for semiochemical-based strategies to gain adoption on a much broader scale than previously achieved.

With larger food supplies required for the population, and concerns growing over the potential hazards of conventional insecticides, it is critical to develop environmentally friendly, effective pest control with lower susceptibility to resistance. The SPLAT platform offers an affordable alternative strategy to replace or complement insecticide-only treatments. Its ease of application, customizable formulation properties, and lessened insecticide inputs make it an excellent tool for both large- and small-scale crop production. Introduction of SPLAT into the "tool kit" of management techniques helps create an integrated approach to insect pest control, allowing for long-term protection, and subsequently improved productivity, of key agricultural crops around the world.

\section{References}

Blomefield, T. (1994). Codling moth resistance: Is it here, and how do we manage it?. Decid. Fruit Grow. 44: 130-132.

Borges, R., Oliveira Da Silva, R., Bernardi, C., Urrutia, W., \& MafraNeto, A. (2015). Noctovi, an effective food based attractant for lepidopteran pests. Poster, presented at Entomological Society of America 2015.

Buhler, W. (2016). Understanding Resistance. http://pesticide stewardship.org/resistance/Pages/understandingresistance.aspx. Accessed 16/03/05.

CDFA, California Department of Food and Agriculture (2010). Red palm weevil, worst known pest of palm trees, detected in Laguna Beach. https://www.cdfa.ca.gov/egov/Press_Releases/ Press_Release.asp?PRnum=10-061. Accessed 16/03/05.

CDFA, California Department of Food and Agriculture (2015). Oriental fruit fly project. https://www.cdfa.ca.gov/plant/PDEP/ treatment/oriental_ff.html. Accessed 16/03/09.

Campbell, B. C., Molyneux, R. J. \& Schatzki, T. F. (2003). Current research on reducing pre- and post-harvest aflatoxin contamination of U.S. almond, pistachio, and walnut. Toxin Reviews 22(2): 225-266.

Carson, R. (1962). Silent Spring, Riverside Press, USA.

El-Sabea, A.M.R., Faleiro, J.R., \& Abo-El-Saad, M.M. (2009). The threat of red palm weevil Rhynchoporus ferrugineus to date populations of the Gulf region in the Middle-East: An economic perspective. Outlooks on Pest Management 20(3): 131-134.
El-Shafie, A.F., Faleiro, J.R., Al-Abbad, A.H., Stoltman, L., \& Mafra-Neto, A. (2011). Bait free attract and kill technology (Hook ${ }^{\mathrm{TM}}$ RPW) to suppress red palm weevil, Rhynchophorus ferrugineus (Coleoptera: Curculionidae) in date palm. Florida Entomol. 94(4): 774-778.

EPPO Global Database: European Plant Protection Organization (2015). Rhynchophorus ferrugineus distribution. https:// gd.eppo.int/taxon/RHYCFE/distribution. Accessed 16/03/02.

Fan, L. T. \& Singh, S.K. (1989). Controlled Release: A Quantitative Treatment. Springer-Verlag, New York.

Hallett, R.H., Gries, G., Gries, R., Borden, J.H., Czyzewska, E., Oehlschlagen, A.C., Pierce Jr., H.D., Angerilli, N.P.D., \& Rauf, A. (1993). Aggregation pheromones of two Asian palm weevils, Rhynchophorus ferrugineus and R. vulneratus. Naturwissenschaften 80: 328-331.

Hern, A., \& Dorn, S. (1999). Sexual dimorphism in the olfactory orientation of adult Cydia pomonella in response to $\alpha$-tarnesene. Entomol. Exp. Appl. 92: 63-72.

Knight, A. L., Brunner, J. F., \& Alston, D. (1994). Survey of azinphosmethyl resistance in codling moth (Lepidoptera: Tortricidae) in Washington and Utah. J. Econ. Entomol. 87: 285-292.

Leblanc, L., Vargas, R.I., MacKey, B., Putoa, R., \& Piñero, J.C. (2011): Evaluation of cue-lure and methyl eugenol solid lure and insecticide dispensers for fruit fly (Diptera: Tephritidae) monitoring and control in Tahiti. Florida Entomol. 94(3): 510-516.

Mafra-Neto, A., de Lame, F.M., Fettig, C.J., Munson, A.S., Perring, T.M., Stelinski, L.L., Stoltman, L.L., Mafra, L.E.J., Borges, R., \& Vargas, R.I. (2013). Manipulation of insect behavior with specialized pheromone and lure application technology (SPLAT®). In Pest Management with Natural Products (Eds. Beck, J. et al.). ACS Symposium Series, American Chemical Society.

Masante-Roca, I., Anton, S., Delbac, L., Dufour, M-C., \& Gadenne, C. (2007). Attraction of the grapevine moth to host and non-host plant parts in a wind tunnel: effects of plant phenology, sex, and mating status. Entomol. Appl. Exp. 122: 239-245.

Mechaber, W. L., Capaldo, C. T., \& Hildebrand, J. G. (2002). Behavioral responses of adult female tobacco hornworms, Manduca sexta, to host plant volatiles change with age and mating status. J. Insect Sci. 2: 1-8.

Mori, B.A. \& Evenden, M.L. (2013). When mating disruption does not disrupt mating: fitness consequences of delayed mating in moths. Entomol. Experi. et Appli. 146: 50-65.

Murphy, S.T. \& Briscoe, B.R. (1999). The red palm weevil as an alien invasive: biology and the prospects for biological control as a component of IPM. Biocontrol News and Information 20(1): $35 \mathrm{~N}-46 \mathrm{~N}$.

OECD (2002). OECD guidance for industry data submissions for pheromones and other semiochemicals and their active substances, Appendix 2: guidance for registration requirements for pheromones and other semiochemicals used for arthropod pest control. http://www.oecd.org/chemicalsafety/pesticidesbiocides/2633680.pdf. Accessed 16/03/07.

Rodriguez-Saona, C. R., \& Stelinski, L. L. (2009). Behaviormodifying strategies in IPM: Theory and practice. In Integrated Pest Management: Innovation-Development Process (Eds. R. Peshin \& A. K. Dhawan), Dordrecht, The Netherlands: Springer Science \& Business Media B.V., 261-312.Roser, M. (2015). World Population Growth, http://ourworldindata.org/data/ population-growth-vital-statistics/world-population-growth/.

Sauphanor, B. \& Bouvier, J. C. (1995). Cross-resistance between benzoylureas and benzoylhydrazines in the codling moth, Cydia pomonella L. Pestic. Sci. 45:369-375. 
Varela, L. G., Welter, S. C., Jones, V. P., Brunner, J. F., \& Riedl, H. (1993). Monitoring and characterization of insecticide resistance in codling moth (Lepidoptera: Tortricidae) in four western states. J. Econ. Entomol. 86: 1-10.

Vargas, R.I., Stark, J.D., Hertlein, M., Mafra-Neto, A., Coler, R., \& Piñero, J.C. (2008). Evaluation of SPLAT with spinosad and methyl eugenol or cue-lure for "attract-and-kill" of oriental and melon fruit flies (Diptera: Tephritidae) in Hawaii. J. Econ. Entomol. 101(3): 759-768.

Weddle, P.W., Welter, S.C., \& Thomson, D. (2009). History of IPM in California pears -50 years of pesticide use and the transition to biologically intensive IPM. Pest Manag. Sci. 65: 1287-1292.

Witzgall, P., Kirsch, P., \& Cork, A. (2010). Sex pheromones and their impact on pest management. J. Chem. Ecol. 36: 80-100.

Wu, J.J., Fan, L., \& Guangqin, L. (2009). Atlas of economic fruit flies (Diptera: Tephritidae). Guangdong Science and Technology Press.

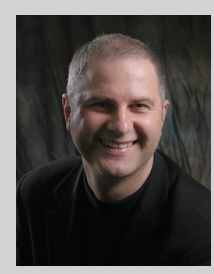

Agenor Mafra-Neto (PhD) is a chemical ecology researcher and entrepreneur in the entomological field of insect chemical ecology, he is the CEO of ISCA Technologies, a company specializing in the development semiochemical solutions for pest management and vector control, as well as robotic smart traps.

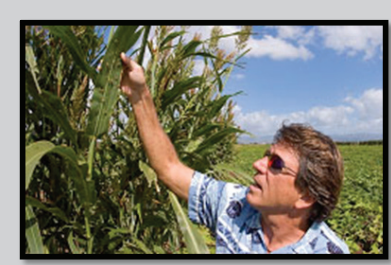

Roger Vargas (PhD) is a research entomologist at the Daniel K. Inouye U. S. Pacific Basin Agricultural Research Center, USDA ARS, Hilo, $\mathrm{HI}$ and holds a position as a University of Hawaii Graduate Faculty. His research interests include fruit fly ecology, behavior, and IPM

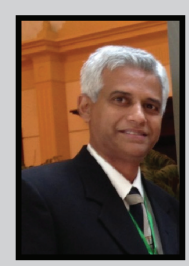

Jose Romeno Faleiro $(\mathrm{PhD})$ a research entomologist specialized in tropical insect pest management, in particular the red palm weevil (RPW), Rhynchophorus ferrugineus Olivier.As the recipient of the prestigious "Khalifa International Date Palm Award" from the Government of the United Arab Emirates in 2015, Dr. Faleiro has a deep insight on both the control and research of RPW in date palms. He is a consultant for the Food and Agriculture Organization (FAO) of the United Nations on RPW in several date producing countries in the Middle East and North Africa. Currently, he works as an FAO consultant on RPW at the Date Palm Research Centre in Al-Hassa, Saudi Arabia.



Abdallah Ben Abdallah (PhD) a research entomologist specialized in the management and control of the red palm weevil (RPW), Rhynchophorus ferrugineus Olivier at Institut National Recherche Agronomique,Tunisia. During the execution of this field trial, Dr.Abdallah was the Chief Technical Advisor of the Food and Agriculture Organization (FAO) of the United Nations project "Establishment of an International Date Palm Research Center in Al Hassa, Saudi Arabia.



Márcio Fernandes Peixoto (PhD) an agronomist at the Instituto Federal Goiano, Rio Verde Campus, GO (Federal Institute of Goias, Green River Campus, GO) with research focus on the following topics: pest management, biological control, tillage, herbicides, cotton crops and sugarcane in the Brazilian cerrado.

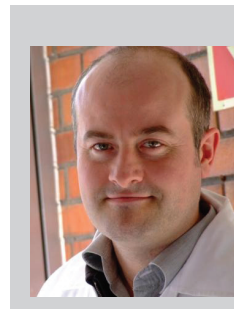

Marcos Bottom is an agronomic engineer researcher at EMBRAPA Grape and Wine Station, a professor of the Graduate Course in Plant Protection at the Federal University of Pelotas, and a professor of Entrepreneurship at the Graduate Course in Business Administration at Cenecista School of Bento Gonçalves. He develops strategies for the integrated pest management of grapes and temperate fruit trees.



Sergio Chidi is the manager of the division of Products and Markets for Arysta LifeScience in São Paulo, Brazil. Mr. Chidi is a graduate of the Agronomy and Crop Science department of Universidade Estadual Paulista Julio de Mesquita Filho/UNESP with an MBA in Management in Agribusiness.

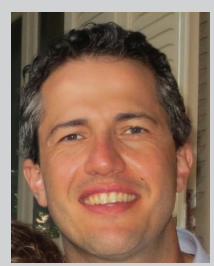

Rafael Borges is the Research Coordinator and Development at ISCA Technologies insemiochemicals, mating disruption, biological pesticides and integrated pest management. He is a professor at the University of Alto Vale do Rio do Peixe and partner of $\mathrm{BN}$ Consulting company acting on integrated production projects (IP), agroforestry systems and renewable energy. He graduated with a BSc in Agronomy from the Universidade Estadual Paulista Julio de Mesquita Filho (2000), an MSc in Plant Production from the University of the State of Santa Catarina (20II), and a PhD in Plant Production from the University of the State of Santa Catarina.



Abdul Moneim Al-Shawaf, works at the Centre for Date Palm \& Dates, Ministry of Agriculture, Saudi Arabia. He conduct research on pests of date palms and particularly red palm weevil. He received a Master of Science in Plant Protection, from the King Saud University, College of Agriculture \& Food Sciences, Al-Riyadh Saudi Arabia, Hofuf, Al-Hasa, Saudi Arabia.

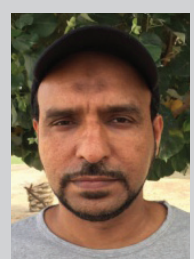

Abdul Moneim Al-Dandan works at the Ministry of Agriculture, Saudi Arabia, conduct research on pests of date palms and particularly red palm weevil, got his bachelor of Science in Plant Protection Dept. of Plant Protection, College of Agriculture \& Food Sciences, at the King Faisal University, Hofuf, Al-Hasa, Saudi Arabia



Abdullah Al-Odhayb works at the Directorate of Agriculture in Al-Qassim, Ministry of Agriculture, Saudi Arabia, as the Supervisor of the RPW Control Programme in Al-Qassim. He obtained his Bachelor of Science in Plant Protection Dept. of Plant Protection, College of Agriculture \& Food Sciences, King Qassim University, in Al-Qassim, Saudi Arabia.

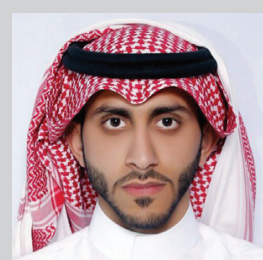

Abdullah Al-Rudayni works at the Directorate of Agriculture in Al-Qassim, Ministry of Agriculture. Saudi Arabia, Directorate of Agriculture in Al-Qassim, Engineer, RPW Control Programme. He got his bachelor of Science in Plant Protection Dept. of Plant Protection, College of Agriculture \& Food Sciences. Al-Qassim, Saudi Arabia, in Hofuf, Al-Hasa, Saudi Arabia. 